\title{
Angle between choice alleys as a critical factor in spontaneous alternation
}

\author{
ROBERT J. DOUGLAS, DENIS MITCHELL, and ROBERT DEL VALLE \\ University of Washington, Seattle, Washington 98105
}

\begin{abstract}
Rats were tested for spontaneous alternation in a variety of mazes differing in the angle between choice alleys. Uniformly high alternation rates were found at all angles from 330 down to 90 deg. At 45 or $0 \mathrm{deg}$, the rates approximated a chance $50 \%$, and at angles between 45 and 90 deg the alternation rates were also intermediate. The hypothesis that the spatial distance between goal regions is the critical factor was rejected, and it was concluded that the angle between alleys is the principal factor determining alternation under these conditions. The results support the idea that alternation in the rat is basically a vestibular phenomenon.
\end{abstract}

In a previous study (Douglas, Mitchell, \& Kentala, 1972), it was found that the tendency of the rat to spontaneously visit opposite alleys in a two-choice maze depended upon the shape of the maze. The alternation rate dropped from about $85 \%$ in a T-maze down to a chance $50 \%$ rate in a maze in which the two choice alleys extended forward, side by side, from the choice point (Maze a in Fig. 1). The results could be explained equally well by either of two hypotheses. The first is that the choice alleys are not sufficiently distant in space in the parallel-arm maze, and the secorid is that the angle between choice alleys is too small. The data gathered in the study above did not allow. a choice to be made between these hypotheses because distance and angle were confounded in the mazes employed in the experiment. In the present study rats were tested for spontaneous alternation in a variety of mazes which differed in the angle between choice alleys and in the distance between goals. The purposes of this study were to generate data which would allow one of the hypotheses to be rejected and to determine whether the alternation rate would be a systematic function of the angle between choice alleys.

\section{METHOD}

\section{Subjects}

Most of the data were gathered from a group of 20 male Wistar rats that were 4 months of age. All were housed in group cages with continuous access to food and water. They were handled twice a day for 10 days prior to testing. Data for the parallel-arm maze (a) were gathered from 22 hooded rats, while a third group of 24 hooded rats was employed for tests at the 60-deg angle (Maze c). The hooded rats were roughly 6 months of age and were individually housed but otherwise treated the same as the first groups of rats above. All three groups were tested in the 180-deg T-maze in order to insure that performance was comparable in this standard situation. As Fig. 2 shows, the three groups were in fact virtually identical in T-maze alternation.

\section{Apparatus}

Eleven different mazes were constructed of 9-mm plywood in the various shapes shown in Fig. 1. The angle between choice alleys varied from 330 to essentially $0 \mathrm{deg}$. The inside dimensions of individual alleys were $11.4 \mathrm{~cm}$ wide, $12.7 \mathrm{~cm}$ high, and roughly $38 \mathrm{~cm}$ long. Alley tops were of wood except at the choice point regions, where wire mesh was employed as a ceiling. Swinging one-way doors were located at the entrances to choice alleys and allowed a rigidly objective definition of alley entry. A vertically sliding door separated a starting region from the remainder of the starting alley. Illumination was provided by a hooded $71 / 2-\mathrm{W}$ light suspended about $30 \mathrm{~cm}$ above the choice point region.

\section{Procedure}

Testing procedure consisted of placing $S$ in the startbox and raising the door to the main alley. $S$ was then allowed to approach the choice point and enter one of the two choice alleys. S was confined to the alley of choice for $30 \mathrm{sec}$ and then removed and replaced in the startbox for a second, identical trial. A test or an observation, thus, consisted of two trials in which $S$ could either alternate (RL, LR) or not (RR, LL). Each $S$ was given one test per day.

Four of the mazes were employed in obverse and reverse form, as can be seen in Fig. 1. The sequence in which the mazes were employed for the Wistar group was: h, e, il, b2, g2, h, b1, j, $\mathrm{g} 1, \mathrm{i} 2, \mathrm{e}, \mathrm{f} 2, \mathrm{f} 1, \mathrm{a}$, and $\mathrm{k}$. In the 22 hooded rat group, $10 \mathrm{Ss}$ were alternately tested in Mazes $h$ and a until a total of fous observations per $\mathrm{S}$ had been made in each maze. The other $12 \mathrm{~S} s$ were alternately tested in Mazes a and $h$ until a total of six observations per $S$ had accumulated. Ss in the 24 hooded rat group were tested alternately in Mazes $h$ and $c$ (half beginning with $h$ and half with c) until a total of four observations per $S$ was achieved in each maze.

\section{RESULTS}

Figure 2 shows that high alternation rates were found at all angles from 330 down to $90 \mathrm{deg}$. The overall mean rate for these angles was $88.8 \%$, and no two data points within this span come close to differing reliably from each other or from the grand mean. Thus, it would appear that an angle of $90 \mathrm{deg}$ is sufficient for alternation to occur at "full strength" and that further increases in angle are superfluous. Note the nearly identical performance of all three groups in the 180-deg T-maze. 


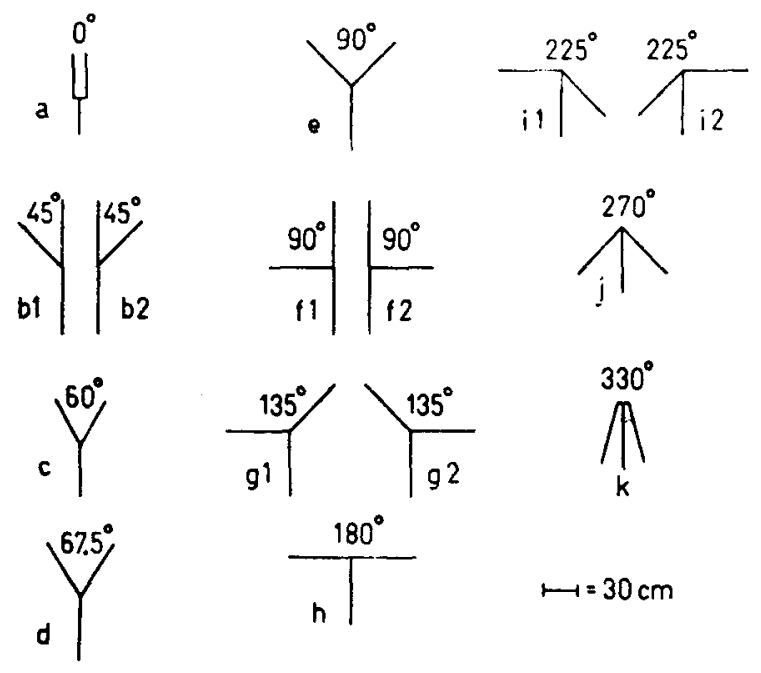

Fig. 1. The mazes, as represented by alley midlines, shown to the indicated scale.

It can also be seen in Fig. 2 that alternation fails to occur at 45-deg angles or less. The mean alternation rates of $45 \%$ (at $45 \mathrm{deg}$ ) and $52.5 \%$ (at $0 \mathrm{deg}$ ) did not, of course, differ reliably from a nominal chance rate of $50 \%$. At angles intermediate between 45 and $90 \mathrm{deg}$, the alternation rates were also intermediate between the extremes above. At $67.5 \mathrm{deg}$ the mean rate was $65 \%$, while at $60 \mathrm{deg}$ it was $62.5 \%$. When the data from these two angles are combined, the distribution of alternation and nonalternation responses differs reliably from that found at the 45-deg angle $\left(\chi^{2}=4.2, \mathrm{p}<.05\right)$ or from a chance $50 \% \quad\left(\chi^{2}=4.8, p<.05\right)$. Similarly, the distribution differs reliably from either that found at $90 \mathrm{deg}$ or from that generated on the basis of $88 \%$ alternation $\left(\chi^{2} \geqslant 9.0, \mathrm{p}<.005\right)$. Thus, alternation is clearly reduced at these intermediate angles, yet it is still above chance. Alternation behavior would thus appear to vanish at some point between 60 and $45 \mathrm{deg}$.

In Mazes b1-b2, $\mathrm{i} 1-\mathrm{i} 2$, and $\mathrm{c}$, the respective angles were 45,60 , and $330 \mathrm{deg}$, but the distance between goal regions was within a centimeter of $43 \mathrm{~cm}$ in all three cases. If distance was the critical factor, then the distributions of alternation and nonalternation responses for the three mazes should have been very similar. In fact, however, the three distributions were reliably different $\left(\chi^{2}=14.1, \quad \mathrm{df}=2, \mathrm{p}<.005\right)$. Thus, the "distance hypothesis" can be confidently rejected. It seems clear from the evidence discussed here that the angle is the critical factor and that a "ceiling effect" occurs at a point near $90 \mathrm{deg}$.

\section{DISCUSSION}

An angle can be measured from the outside or the inside, and our 330-deg maze could conceivably be called $30 \mathrm{deg}$. It is clear from Fig. 2, however, that it is the outside angle which is critical. This is reasonable because spontaneous alternation is largely a vestibular phenomenon (Douglas, 1966a, b). The outside angle is the one through which the animal and his semicircular canals must turn if the nose is pointed successively at each choice alley. These observations, thus, add still more evidence to a growing body of facts supporting the idea of inertial navigation as a crucial factor in many different kinds of rat behavior from spontaneous alternation to complex maze learning and even to shock avoidance conditioning (see Douglas, 1966a, b; Olton \& Isaacson, 1968). George Elting has recently discovered in this laboratory (unpublished data) that rats trained to perfection in a multiple $\mathrm{T}$-maze have an apparently permanent regression to prelearning performance if the maze is very slowly rotated on a turntable. A similar disintegration of maze learning was found by Watson (1907) when he rotated his maze between trials but not when the maze was moved to the opposite end of the room but kept in its original spatial orientation. What is surprising, however, is that the system appears to break down at such a wide angle as $45 \mathrm{deg}$. The reason for this lack of precision may be that our Ss were handled and possibly slightly disoriented between trials. In nature or in a situation where handling is avoided, the rat's inertial navigational system might be much more accurate than the present results indicate.

In some of the mazes used in the present study, one of the choice alleys was, in effect, a continuation of the starting alley. The reader might justifiably suspect that rats might have a tendency to run straight ahead in such maze configurations and that this tendency might account for the lack of alternation at $45 \mathrm{deg}$. An analysis of the data reveals, however, that our rats had no such tendency. First, our rats rarely ran through the choice point region but instead typically stopped, made vicarious alley entries, etc., before entering an alley. Second, in those cases where a straight-ahead response was possible, the rats made this response only $47.5 \%$ of the time on their initial trials in the maze. Third, one of the 90-deg mazes (e) was forked like a Y, while the other

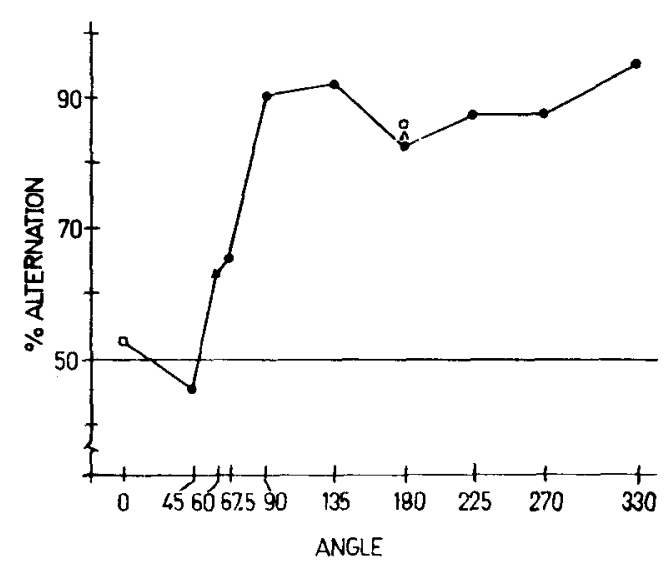

Fig. 2. Spontaneous alternation as a function of choice alley angle. The 20 Wistar rats are represented by solid circles, the 22 hooded rat group by open squares, and the 24 hooded rat group by open triangles. 
two (f1, f2) were of the "straight-ahead" variety. The mean alternation rates were $87.5 \%$ for the "forked" maze and $92.5 \%$ for the "straight-ahead" mazes. The data from all three versions of $90 \mathrm{deg}$ are combined in Fig. 2 because of this similarity. Finally, both the 60 and 67.5-deg mazes were of the $Y$ type, and yet alternation was significantly reduced in these mazes. Thus, it seems clear that the lack of alternation at $45 \mathrm{deg}$ was not due to the specific design of the maze.

These results are relevant to the design and analysis of maze learning studies. Figure 2 suggests, for example, that a rat being trained in a $\mathrm{T}$ or a wide $\mathrm{Y}$ maze will begin with a vestibular or vestibulo-spatial "hypothesis," whereas in a very narrow $Y$ or in a parallel-arm maze, he will not. This is supported by the observation by Richman, Gardner, Montgomery, and Benewicz (1970) that rats do learn a position habit faster than a brightness task in the T-maze. Waller (1968) found the reverse to be true in a parallel-arm maze.

The present results should not be taken to imply that rats will not under any circumstances alternate in narrow angle mazes. Richman, Chappell, Crowe, Perry, and Redfearn (1970) reported low-rate but above chance alternation when one alley of a parallel-arm maze was black and the other white. In the present study, however, the rats did not avail themselves of visual cues which might have been provided by numerous irregularities in the wooden walls of the mazes or of unseen olfactory cues which might conceivably have differentiated the alleys.

Finally, these results added to those in the literature suggest a revision of thinking on the subject of whether spontaneous alternation is a "stimulus" or a "response" variable. Early studies (Montgomery, 1952; Glanzer, 1953) as well as later ones (Douglas, 1966) demolished a Hullian version of the response alternation idea. But numerous studies suggesting a vestibular basis for alternation would appear to have brought back the concept of response alternation in a new guise. The vestibular system is usually stimulated by the animal's responses or movements. But the concept of inertial navigation (Barlow, 1970) suggests that this information is employed in the creation of a "spatial map," without which navigation is impossible. Thus, it would appear to be more fruitful to think of rat behavior as being the resultant of numerous interactions between response and stimulus (or conceptual) variables, all of which are important for the final production of behavior.

\section{REFERENCES}

Barlow, J. S. Vestibular and non-dominant parietal lobe disorders. Diseases of the Nervous Sy stem, 1970, 31, 667-673.

Douglas, R. J. Cues for spontaneous alternation. Journal of Comparative \& Physiological Psychology, 1966a, 62, 171-183.

Douglas, R. J. Spontaneous alternation and middle ear disease. Psychonomic Science, 1966b, 4, 243-244.

Douglas, R. J., Mitchell, D., \& Kentala, D. Spontaneous alternation as a function of maze configuration. Psychonomic Science, 1972, 27, 285-286.

Glanzer, $M$. The role of stimulus satiation in spontaneous alternation. Journal of Experimental Psychology, 1953, 45, 387-393.

Montgomery, K. C. A test of two explanations of spontaneous alternation. Journal of Comparative \& Physiological Psychology, 1952, 45, 287-293.

Olton, D. S., \& Isaacson, R. L. Importance of spatial location in active avoidance tasks. Journal of Comparative \& Physiological Psychology, 1968, 65, 535-539.

Richman, C. L., Chappell, L., Crowe, D., Perry, P. C., \& Redfearn, L. Spontaneous alternation in rats as a function of brightness cues. Psychological Reports, 1970, 27, 356-358.

Richman, C. L., Gardner, J. T., Montgomery, M. D., \& Benewicz, K. L. Effects of body weight loss on position and brightness discrimination tasks. Learning \& Motivation, 1970, 1, 218-225

Waller, C. T. Effects of magnitude of reward in spatial and brightness discrimination tasks. Journal of Comparative \& Physiological Psychology, 1968, 66, 122-127.

Watson, J. B. Kinaesthetic and organic sensations: Their role in the reactions of the white rat to the maze. Psychological Review, 1907, 8(Supplement 33), 1-100.

(Received for publication March 8, 1974; accepted April 23, 1974.) 